\title{
Experiências vividas pelo cônjuge cuidador da esposa em tratamento psiquiátrico
}

\author{
Eraldo Carlos Batista \\ Faculdade Católica de Rondônia, Porto Velho, RO, Brasil \\ Pontifícia Universidade Católica do Rio Grande do Sul, Porto Alegre, RS
}

\begin{abstract}
Resumo
O objetivo deste estudo foi compreender as experiências vividas pelo homem cuidador familiar da esposa em tratamento psiquiátrico. Como método utilizou-se uma abordagem qualitativa do tipo descritivo-exploratório de orientação fenomenológica. Foram realizadas entrevistas semiestruturadas com seis cônjuges cuidadores do sexo masculino da região da Zona da Mata do Estado de Rondônia. Nos discursos dos participantes, puderam-se perceber as dificuldades encontradas no seu cotidiano, como: a preocupação em suprir as necessidades básicas da família; a coordenação das atividades domésticas diárias; a administração da medicação à esposa em sofrimento; o acompanhamento aos serviços de saúde; e a convivência com os comportamentos problemáticos e episódios de crise da esposa. Foi possível, ainda, observar que o papel de cuidador tem gerado sobrecarga física e emocional no cônjuge, levando-o a um estado de sentimento de culpa pelo agravamento da doença da esposa e, consequentemente, ao seu adoecimento mental.
\end{abstract}

Palavras-chave: cuidador familiar; sofrimento psíquico; saúde mental.

\section{Experiences undergone by the spouse caregiving the wife in psychiatric treatment}

\begin{abstract}
The objective of this study was to comprehend the experiences undergone by the husband that is caregiving his wife in psychiatric treatment. As method, we used a qualitative approach of descriptive and exploratory type of phenomenological orientation. It was performed semi structured interviews with six male spouses/caregivers from the Zona da Mata region in the State of Rondônia. In the participants'statements, one can notice the difficulties found in everyday life, such as: the guarantee of the family's basic needs; coordination of house chores; administration of the wife's medication; the monitoring of health services; living with problematic behaviors and episodes of crisis. It was also possible to observe that the role of the caregiver has generated physical and emotional burdens on the spouse, taking him into a state of guilty due to theworsening of the wife's sickening and, consequently, to his own mental distress.
\end{abstract}

Keywords: family caregiver; psychological distress; mental health.

\section{Introdução}

A relação conjugal está pautada na confiança, na responsabilidade, no dever e nas obrigações cotidianas e no cuidado com o outro. Dessa forma, percebe-se que os aspectos conjugais são importantes para a qualidade das relações familiares. Contudo, a relação fica desestabilizada quando a família enfrenta o adoecimento de um dos cônjuges, levando o outro a desempenhar o papel de cuidador principal.

$\mathrm{O}$ cuidado de um familiar em tratamento psiquiátrico provoca mudanças em todos os campos da vida do cuidador. As dificuldades ocasionadas pela função exclusiva de cuidado afetam diretamente a sua qualidade de vida (GOMES; SILVA; BATISTA, 2018). Quando o cuidador principal é o esposo ou esposa, acrescentam-se a essas mudanças as implicações na vida profissional e na saúde física e mental dos cônjuges (NORGREN et al., 2004).

O surgimento de uma doença mental no cônjuge agrava drasticamente o quadro de insegurança e desconforto no parceiro, o que representa, em geral, um forte abalo. Para a maioria das pessoas que se encontra nessa situação, a enfermidade do cônjuge significa uma grande ruptura na

\footnotetext{
^Endereço para correspondência: Faculdade Católica de Rondônia, Departamento de Psicologia. Rua Gonçalves Dias, 290, Centro - Porto Velho, RO - Brasil. CEP. 76940000. E-mail: eraldo.cb@hotmail.com

Os dados completos do autor encontram-se ao final do artigo.
}

trajetória existencial. A vivência de catástrofe desestrutura as formas de lidar com as situações do cotidiano (MELMAN, 2001). Em um casal, o reconhecimento da doença do outro, ou de estar doente, fundamenta-se na interpretação e na interdiscursividade que ambos dão às suas próprias angústias (LISBOA; FÉRES-CARNEIRO, 2008).

Uma vez que o cônjuge assume o papel de cuidador, ele necessita fazer diversos reajustes e assumir compromissos que o impedem de atingir o seu pleno potencial no trabalho, nas relações sociais e no lazer. Ou seja, sobre ele recai, predominantemente, o peso de prestar cuidados não só ao cônjuge enfermo, mas a todo o grupo familiar. Intermedeia, ainda, a ligação entre o cônjuge doente e o médico (MACIEL et al., 2009). Todos esses fatores acabam, na maioria das vezes, comprometendo a relação conjugal, gerando consequências negativas não só para a relação, mas também para a saúde mental do cônjuge cuidador.

Rosa (2011, p. 264) afirma que “[...] o transtorno mental vai afetar sobremaneira o grupo familiar à medida que atinge aqueles sujeitos que ocupam um papel estruturante na organização familiar, ou seja, um dos cônjuges." Nesse caso, quando se trata do adoecimento de um dos cônjuges, o impacto que o sofrimento psíquico provoca no parceiro tem consequências variadas conforme o gênero que ocupa na relação. 
Quando o marido é acometido pelo transtorno mental, há uma tendência ao comprometimento da renda familiar, o que provoca um deslocamento do papel da mulher, cujas atribuições na divisão do trabalho ficam comprometidas, considerando-se que ela também precisa gerar renda, o que até então era função do marido. Além disso, a condição moral o homem na família tende a ficar vulnerabilizada, pois, historicamente, a enfermidade está relacionada à fragilidade, característica culturalmente associada à mulher (ROSA, 2011).

No entanto, a esposa se encontrar em sofrimento psíquico afeta muito mais a família. Quando o homem assume o papel de dedicar considerável parcela do seu tempo para cuidar dela, ele passa a sofrer privações econômicas e sociais, pelo comprometimento de sua força produtiva, além dos encargos que sobre ele recaem, que vão desde as dificuldades econômicas às reações emocionais e ao estresse em face de um comportamento perturbado (MACIEL et al., 2009).

Também se percebem diferenças na forma de assistência ao familiar doente de acordo com a posição que o cuidador ocupa na família. Quando a cuidadora é do gênero feminino, ela se vê obrigada a participar dos dispositivos de tratamento (participação de grupos, atendimentos e tudo o que for sugerido como estratégia de assistência) do seu ente adoecido. Já o cuidador do gênero masculino se mantém distante, tanto do dispositivo de tratamento quanto da prestação de assistência ao familiar em casa. Em algumas situações, quando o cônjuge do sexo masculino assume o encargo de cuidador, "é comparado a um pai, como se estivesse extrapolando o seu papel" (ROSA, 2011, p. 268).

Essa diferença de gênero na forma de cada cônjuge exercer o papel de cuidador também se explica pelo viés da construção social do cuidado, atribuído de forma genuína à figura feminina. No que se refere ao cuidador de pessoa com transtorno mental, a literatura tem apontado que a maioria dos membros desse grupo é formada por mulheres (LACCHINI, 2011; SANT'ANA et al., 2011; DIAS, 2011; CARDOSO; GALERA; VIEIRA, 2012; SILVA; DIMENSTEIN; LEITE, 2013; BATISTA et al., 2013; DOURADO et al., 2018).

Essa questão demonstra a relação que a produção histórica do cuidado mantém com a divisão social do trabalho presente na sociedade moderna, a partir do século XVIII, quando a divisão de gênero do trabalho estabeleceu lugares sociais conforme o sexo, forjando-se, assim, uma hierarquia entre as pessoas, a partir do gênero, em que a função da mulher na esfera do trabalho foi associada ao âmbito privado doméstico, e ela passa, então, a ser responsável pelas funções domésticas, de educadora e de prestadora de cuidados para o homem e seus filhos (SEVERO et al., 2007; ROSA, 2011).

Um estudo realizado por Silva, Dimenstein e Leite (2013) com 11 cuidadores familiares, moradores da zona rural das cidades de Cajazeiras, Bom Jesus e Joca Claudino, do Alto Sertão do Estado da Paraíba, mostrou que as mulheres, além de agricultoras, acumulam as funções de cuidadoras dos familiares em tratamento psiquiátrico e dos afazeres domésticos. Para Rosa (2011), embora os parentes consanguíneos colaborem para a efetivação do cuidado, nem todos contribuem proporcionalmente. Enquanto as mulheres oferecem um cuidado mais afetivo, os homens geralmente se encarregam da garantia do alimento ou da compra de outros mantimentos para a casa, assumindo a condição de provedor da unidade doméstica (ROSA, 2011; SILVA; DIMENSTEIN; LEITE, 2013).

Entretanto, o número de homens que desempenha papel de cuidador vem crescendo, embora pouca atenção tenha sido dada a eles nos estudos (BATISTA et al., 2013). No campo da saúde mental, estudos que abordam a questão do homem como cuidador familiar principal têm sido pouco evidenciados; os números são ainda menos expressivos quando o cuidador é o cônjuge.

Quando se trata de sofrimento psíquico grave da esposa, em muitos casos é o marido que assume o papel de cuidador. Os cônjuges são os principais atores a assumirem o cuidado, mesmo que movidos por uma "obrigação matrimonial", pelo projeto de vida comum assumido em razão do casamento e pelo compromisso de estar junto na saúde e na doença (CATTANI; GIRARDON-PERLINI, 2004).

Ao exercer essa nova função, o esposo amplia os papéis assumidos na família, uma vez que ele passa a desempenhar uma série de funções dentro de casa. Observa-se que há uma carência de estudos empíricos e sistemáticos acerca dos fatores associados ao grau de adoecimento mental dos cuidadores familiares, avaliados separadamente nos grupos de homens e mulheres cuidadores. Assim sendo, o presente estudo busca avançar, no sentido de trazer visões mais abrangentes do cuidador familiar no campo da saúde mental, a partir da perspectiva masculina, que na literatura tem permanecido como figura marginal no âmbito do cuidado.

Considerando o exposto, este artigo teve por objetivo compreender as experiências vividas pelo esposo cuidador familiar da parceira que se encontra em tratamento psiquiátrico.

\section{Método}

Trata-se de um estudo descritivo-exploratório, qualitativo, de caráter fenomenológico (MOREIRA, 2004). Foram realizadas entrevistas, no período de setembro a novembro de 2014, com seis cônjuges do sexo masculino cuidadores das esposas em tratamento psiquiátrico atendidas em um CAPS da Zona da Mata do Estado de Rondônia. Considerou-se como principal cuidador a pessoa que provê ao paciente os principais cuidados primários, como alimentação, vestuário, higiene, administração de remédios e finanças.

Para a coleta de dados, foi utilizado um questionário, que visou coletar a caracterização desses cuidadores, e entrevistas semiestruturadas, segundo proposto por Minayo (2010), que foram gravadas e transcritas na íntegra em "diário de campo" para serem analisadas, no qual foram anotadas todas as informações e impressões obtidas, com a finalidade de complementar os dados das entrevistas. 
A idade dos cuidadores variou entre 50 e 71 anos. A duração da prestação de cuidados observada, em anos, teve um intervalo de dois a 24 anos, e o tempo de relacionamento conjugal, entre oito e 47 anos. Todos que concordaram em participar leram e assinaram o termo de consentimento livre e esclarecido (TCLE).

As entrevistas foram agendadas previamente no CAPS e realizadas nas residências desses cuidadores, por se considerar que nesse local eles se sentiriam mais à vontade para falar sobre suas vivências. As entrevistas transcritas foram identificadas pela letra $\mathrm{C}$ (cuidador) e por números.

Como forma de compreender e interpretar as vivências do cuidador nesta pesquisa, o aprofundamento foi orientado pela proposta de análise fenomenológica elaborada por Sanders (1982). Primeiramente, foram realizadas as entrevistas com o cuidador e, após o encerramento de cada entrevista, foi ouvida a gravação, com atenção para cada relato do familiar, lembrando a expressividade deste e realizando anotações no caderno de campo, com o objetivo de tornar mais clara a interpretação (FLICK, 2009). Ao término da coleta das informações obtidas com os participantes, fez-se a transcrição literal de todas as entrevistas para a descrição do fenômeno tal como revelado; em continuidade, foram identificados os temas ou invariantes que emergiram das falas dos cuidadores.

Eleitos os temas, o processo de encontro com as falas levou ao recorte de trechos que pudessem elucidar elementos necessários para a compreensão e interpretação do fenômeno. Após a posse de um repertório individual de significações, procurou-se perceber os pontos comuns entre os relatos e alinhá-los para que permitissem a construção dos núcleos de sentido, a partir da dimensão representativa do fenômeno. Para a discussão dos dados, foi utilizado o referencial teórico relacionado ao estudo.

Esta pesquisa foi aprovada pelo Comitê de Ética em Pesquisas (CEP) da Universidade Federal de Rondônia (UNIR), sob o parecer de $n^{\circ} 650.879$.

\section{Resultados e discussão}

Considerando as informações obtidas a partir das entrevistas correlacionadas aos objetivos da pesquisa, foram identificadas as temáticas emergentes, que contribuíram para a compreensão das experiências vividas pelo cuidador familiar cuja esposa se encontra em sofrimento mental grave, objetivo principal desta pesquisa. Nessa perspectiva, as categorias analisadas neste estudo abordaram os seguintes temas: dificuldades enfrentadas no cuidado cotidiano; sobrecarga familiar e adoecimento do cuidador; e sentimento de culpa pelo adoecimento da esposa.

\section{Dificuldades enfrentadas no exercício do cuidado}

O impacto inicial da doença, provavelmente, é o que causa maior desorganização, exigindo maior sensibilidade do cônjuge cuidador para que possa compreender a dimensão existencial do momento, a fim de cuidar da esposa em sofrimento de modo eficiente. As entrevistas revelaram que a maioria dos cuidadores, ao relatarem as suas atitudes perante os primeiros sintomas da doença, afirmou não perceber que se tratava de um transtorno mental grave.
Difícil [silêncio]. Não é fácil, não [silêncio]. A gente fica meio nervoso. Dá um remédio pra ela e vai controlando. Tem vez [pausa], como agora mesmo, ela tá enjoada de novo, tem dia que ela está "terrível" [em crise] [...] Tem época que é de "veneta" [imprevisível]. Hoje mesmo ela chorou muito [...] um estresse mínimo já começa esse chororô $(\mathrm{C} 1$, informação verbal).

Ao se deparar com o sofrimento vivido por parte dos cuidadores, amplia-se a compreensão e percebe-se que essa questão parece estar fazendo parte de uma espécie de representação e imaginário social desse ser que precisa ser desmistificada. Por essa razão, ao repensar seu lugar e função enquanto indivíduo do gênero masculino na sociedade, o homem tem a oportunidade de refletir sobre suas necessidades individuais. Consequentemente, este homem, além da função de cuidador principal da esposa, passa a se dedicar, como afirmam Arruda e Lima (2013), não somente à subsistência da casa, como também ao desejo de participar, mais diretamente, da construção de um ambiente de bem-estar em sua família.

No início pra você lidar com alguns sintomas que aparenta nessa doença, eu falo que é doença porque é doença, você não sabe o que fazer, se você vai conversar, se você vai fazer alguma outra coisa, se vai virar as costas e sair de perto pra não estar brigando. É difícil, ainda estou me adaptando [...] (C2, informação verbal).

O desconhecimento dos sintomas por parte do cuidador e o fato de este se encontrar em um estado de desespero, sem saber qual atitude tomar para lidar com o sofrimento da esposa, são duas das dificuldades apontadas pelos depoimentos. Revelam mais do que informações, configurando-se, essencialmente, relatos de vivências de afeto, emoção, dor e, sobretudo, tristeza, um fenômeno que se estabelece no âmbito da relação sofrimento-cuidado e que termina por gerar emoções muito fortes, conforme relatos dos depoentes por ocasião das entrevistas.

Apesar de que eu acho que a doença dela não é uma doença grave, é uma doença no início, mas tem as dificuldades, tem hora que não sei o que fazer. Vou fazer o quê pra ela agora, vou conversar o quê com ela, vou fazer o quê pra tirar ela desse nervosismo, dessa ansiedade, dessa angústia, e aí que você se perde, e aí, poxa vida... [olhos lacrimejados] (C2, informação verbal)

Nesse contexto, o choro desse cuidador pode significar o sentimento de impotência em lidar com a doença da esposa, na medida em que expressa tristeza pela falta de desempenho no cuidado do outro, revelando medo e insegurança por precisar cuidar da parceira e sentir-se despreparado para isso.

A força para continuar enfrentando as dificuldades, para alguns dos participantes, vem da crença de que a doença é uma missão que eles devem assumir.

[...] hoje tá melhor, mas no começo foi bem difícil. [...] hoje ela tá quase normal, tirando os dias em que ela acorda meia [...] tem vez que ela acorda meio variando das coisas [em crise] [...] (C5, informações verbais).

Tem dia que ela tá boa. Tem dia que não quer nada com nada. Tem que passar a entender e deixar passar o tempo. 
Tem que ser do jeito dela, não quer, não quer [...] Aí, quando está em crise, não quer nada com nada, aí tem que suportar e esperar ela melhorar (C6, informações verbais).

No entanto, é interessante notar nesses relatos que, mesmo quando existe por parte do esposo o reconhecimento do cuidado como seu papel, poucos fizeram referência sobre como poderiam ajudar as esposas nesses momentos. Isso se justifica pela referência ao fato de terem que suportar tais situações.

Outro fator importante a ser ressaltado é o convívio do cuidador com a agressividade da parceira. Além das preocupações referentes à saúde da esposa em sofrimento psíquico, alguns cuidadores convivem com comportamentos agressivos e violentos da parceira, o que representa um sofrimento para eles, como mostra o depoimento seguinte:

[...] teve uma época que ela "surtou" o juízo [entrou em crise]; fui dar um remédio pra ela, ela não queria tomar. Ela estava com uma lamparina na mão, me atirou a lamparina, me queimou tudo. O sinal está aqui, olha [na volta superior do corpo, barriga e braços]. O meu corpo queimou tudo, ela é muito agressiva ( $\mathrm{C} 1$, informação verbal).

Para Rosa (2011, p. 282), a relação da família com o enfermo psicótico tende a ser mais dramática, pois os sintomas são mais intensos e ameaçadores à segurança do grupo. Acrescenta, ainda, que, quanto mais medo o cuidador tem da pessoa enferma, mais se restringe sua área de circulação. Normalmente, nessas circunstâncias o cuidador isola-a no ambiente doméstico ou recorre à internação integral.

\section{Sobrecarga e adoecimento do cuidador}

Sob esse tema, agruparam-se relatos que explicitavam as dificuldades dos cônjuges cuidadores diante da sobrecarga que enfrentavam no cotidiano. Diferentes fatores estiveram associados à sobrecarga física e psicológica, como: a esposa não desempenhar atividades mínimas em casa, a presença de comorbidade e o número de comportamentos problemáticos da enferma. Aparecem, ainda, como fatores associados à sobrecarga: o cuidador não possuir renda; relatar doença resultante do papel de cuidador; o paciente ter doença física; o cuidador abdicar da sua vida social e profissional.

Melman (2001) afirma que o familiar cuidador tem uma sobrecarga ainda maior do que os outros membros da família, pois, além das responsabilidades naturalmente assumidas, também é vítima de exclusão, de preconceito, de sentimentos de dor e de sofrimento, de forma que associa os sintomas da enfermidade a algo ruim. Há, ainda, o fato de que o surto psicótico de um paciente rompe e desorganiza a vida da família, representando o colapso dos esforços e o atestado de incapacidade de cuidar adequadamente do outro.

Muitos dos cuidadores destacaram a relação de cuidar como uma experiência de sofrimento e desgaste em múltiplas dimensões, implicando perdas físicas, emocionais e nas interações sociais. O que se pode perceber é que o provimento de cuidado como atividade de sobrecarga afeta o cuidador tanto em suas condições físicas quanto mentais.

Exemplos dessas construções são dados na fala a seguir:

[...] antes [do adoecimento da esposa] eu tinha que trabalhar, pra manter a casa, depois eu me aposentei. Agora a tarefa ficou do mesmo jeito, porque eu que tenho que fazer tudo: lavar roupa, fazer comida, dar banho, tenho que fazer de tudo, buscar remédio, ir comprar comida, ir atrás de tudo (C1, informação verbal).

Notou-se que, quando há maior disponibilidade do cônjuge para o cuidado na família, este é voltado para a assiduidade ao tratamento medicamentoso em domicílio, para os cuidados com a higiene, para evitar acidentes provocados por objetos perigosos e para a atenção em contexto de crise. Tal fato constitui uma permanente fonte geradora de sofrimento para o cuidador, uma vez que culturalmente essas atividades domésticas não fazem parte do universo masculino.

Nesse sentido, ter que atuar como um agente potencializador na administração das atividades domésticas cotidianas representa para esses homens uma intensa sobrecarga subjetiva, que causa sofrimento psíquico (ROSA, 2011). Para alguns dos entrevistados, eles estão fazendo o que era "obrigação" da mulher, como fica evidenciado na fala a seguir:

Olha, digamos que quando ataca [a esposa entra em crise], eu tenho que fazer tudo: almoço, limpar casa, lavar roupas... E isso é tudo obrigação que ela fazia; agora eu tenho que fazer, porque se colocar uma pessoa de fora pra fazer tem que explicar tudo os motivo, aí fica mais difícil de fazer isso, explicar pra pessoa o que está se passando com ela. Seria mais constrangedor pra ela do que se a gente pegar e fazer (C6, informação verbal).

Outro fator que chamou a atenção foi a presença de sobrecarga psicológica percebida pelos cuidadores em consequência da permanência em casa perante a esposa em sofrimento psíquico, fato que parece ser preponderante para o adoecimento do marido.

Eu tenho que cuidar disso aqui [a esposa] [...] me deu uma dor nas "cadeiras" [expressão popular]. Até me emociono em falar disso, que foi muito ruim [silêncio]. Não, tudo bem [...] Só estou querendo me desabafar, né, certo, é bom eu me desabafar (C4, informação verbal).

Para Campos e Soares (2005), não seria inoportuno afirmar que muitos cuidadores se tornam usuários diretos de serviços de saúde mental diante da sobrecarga emocional vivenciada.

Em vários momentos das entrevistas apareceu, na fala dos cuidadores, a questão do trabalho profissional como uma importante referência para a "construção" do que significa "ser homem"; ter trabalho e emprego que lhes garantam o sustento da família parece ser ainda uma das principais bases de sustentação da "subjetividade" e da “condição masculinas" (BORIS, 2011). 
Os depoimentos a seguir (dos entrevistados C3 e C6) revelam a importância do trabalho e da vida social na construção do gênero masculino:

A gente se sente... Eu não posso sair pra canto nenhum, porque além de tudo eu não tenho dinheiro pra ir numa festa, igual amanhã mesmo, tem festa, jogo de futebol, [torneio], a turma [os amigos] vai, e eu sou obrigado a ficar em casa. Falei com o outro cara que mexe também [técnico de futebol amador]: "Você toma conta do time lá, porque a mulher tá assim e assim, e eu estou sem condições de chegar lá e passar o dia inteiro." Porque é assim de manhã até de tarde e noite [a esposa encontrava-se em crise]. Também não tenho dinheiro, não tenho nada. Já pensou um homem viver assim? Então, a gente fica assim, com a cabeça meio perturbada. Mas depois esquece, vai seguindo pra frente (C3, informação verbal).

Observa-se que esses cuidadores vivenciam uma situação de frequente instabilidade em relação a seus empregos e, consequentemente, isso afeta suas vidas financeiras. Muitos dos entrevistados sobrevivem apenas com o salário da aposentadoria da esposa, o que eventualmente os leva a depender do benefício auxílio-doença da parceira, e tal situação parece incomodá-los muito, pois a dependência faz com que esses homens se sintam inferiores aos outros e, até mesmo, à própria esposa. Desse modo, percebe-se que o lugar social no qual esses cuidadores estão inseridos está ligado ao sofrimento psíquico, às suas péssimas condições econômicas e à inexistência do mundo do trabalho. Uma (ou a única) forma de se afastarem desse lugar de sofrimento e se verem novamente como indivíduos produtivos seria ocorrer a recuperação da saúde da esposa. "Se ela 'ficasse boa' a minha vida seria outra" (C3, informação verbal). Para esse cuidador, a esperança de que sua esposa melhore se apoia na ideia de que ela possa vir a se tornar mais independente, voltar às suas atividades diárias, para ele retornar ao seu trabalho.

Estudos realizados por Batista et al. (2013) com cuidadores de pacientes psiquiátricos corroboram esses achados. No referido estudo, os resultados revelaram que os cuidadores do sexo masculino relataram sentir maior peso financeiro quando comparados aos relatos das mulheres cuidadoras. Por isso, além da carga direta em lidar com a pessoa que se encontra em sofrimento psíquico, é preciso levar em conta as oportunidades perdidas por eles. "Olha, eu tinha um escritório de contabilidade e fui obrigado a parar, né, porque não tinha como administrar as duas coisas, cuidar do escritório e cuidar dela" (C6, informação verbal).

Maciel et al. (2009) afirmam que as famílias que têm um membro em sofrimento mental grave fazem diversos reajustes e assumem compromissos que impedem outros familiares de atingir o seu pleno potencial no trabalho, nas relações sociais e no lazer. “O que gosto mesmo é só futebol [...] mas não vou mais [silêncio]; não vou em boteco, em lugar nenhum. Na verdade faz muito tempo que não vou nem na igreja" (C4, informação verbal).

Para a maioria dos cuidadores, o afastamento das atividades de lazer é o que traz maior prejuízo às suas vidas. Para muitos, a falta da liberdade de ir e vir, em alguns momentos, desencadeia uma condição de adoecimento, de sentimentos negativos com relação ao cuidado. As falas dos cuidadores a seguir descrevem esses sentimentos de insatisfação com o seu papel.

Eu morava no sítio [silêncio] [...] agora "tocar" de viver assim, sem poder sair, eu gostava de pescar; tudo isso acabou. [...] agora não posso fazer nada disso [silêncio], a gente se distraía, quando chegava o domingo ia pescar, era meu divertimento [silêncio]. Minha festa era pescar, passar o dia à beira do rio. Agora nada disso eu posso fazer [...] $(\mathrm{C} 1$, informação verbal).

Nesses cenários, observou-se que o envolvimento e a dedicação exigidos dos cuidadores para prestar cuidado às esposas fizeram com que eles negligenciassem atividades que lhes traziam satisfação, como passeios, diversões e esportes. Há, assim, alteração nas relações sociais do esposo.

Durante os encontros com os cuidadores, foi possível observar que, ao relatarem sobre as atividades prazerosas das quais tiveram que abdicar em prol do cuidado com a esposa, apresentavam, em alguns momentos, olhares perdidos no tempo, como se buscassem alguma coisa que se foi. De acordo com Melman (2001, p. 80), “[...] é comum observar os familiares se distanciando das atividades sociais, deixando de comparecer a festas e eventos culturais, restringindo visitas à casa de amigos próximos e parentes."

É importante ressaltar que o exercício do cuidado produz nesses homens, além da sobrecarga física, um consequente sofrimento psíquico, percebido na dificuldade em operar planos, em definir o sentido da vida e no sentimento de impotência e vazio, o que os torna incapacitados para interagir na sociedade e, em casos extremos, os leva à perda de sua condição de cidadãos.

Conviver com a instabilidade do comportamento da esposa, com o sentimento de insegurança, repercute em raiva e estresse. Observa-se, a seguir, na verbalização do entrevistado, a presença desses sentimentos que envolvem o seu cotidiano: “[...] tem hora que o estresse é demais, parece ficar até meio [pausa] faz raiva. Já tem hora a pressão da gente sobe, a raiva é demais." (C1, informação verbal).

Os comportamentos e os sintomas da esposa levam à sobrecarga, pois resultam em desorganização da rotina familiar e em tarefas extras de cuidado para os cuidadores, acarretando fatores que geram um estresse crônico e com os quais os familiares precisam aprender a lidar, principalmente porque dispõem de pouco suporte social (CAMPOS; SOARES, 2005), conforme trecho citado no parágrafo anterior, que representa a maior parte dos relatos dos participantes.

A angústia causada pelas dificuldades em lidar com os comportamentos também é expressa pelos cuidadores. Tudo indica que eles não são afetados apenas pelas atividades extras que precisam assumir, em razão dos comportamentos disfuncionais das esposas, mas também pelo estresse psicológico que essa sobrecarga acarreta.

Tem vez, quando ela está em crise, a pressão da gente sobe, dá aquela ansiedade e a gente não pode fazer nada. O melhor jeito é deixar a pessoa [a esposa] falar e cuidar pra não deixar ela se machucar. São coisas até difíceis de explicar, 
porque a gente vai vivendo assim e vai levando [...] (C6, informação verbal).

Para Melman (2001), do ponto de vista emocional, o estresse, a instabilidade, a insegurança e os conflitos frequentes nas relações fazem parte do cotidiano dessas pessoas.

Às vezes eu durmo, outras vezes começa a dar uma perturbação na minha cabeça aí já perco sono. Vou dormir de madrugada mais ou menos, durmo uma horinha de madrugada e já é hora de se levantar. Eu fico pensando em muita coisa, fico virando de um lado para o outro, pensando nos problemas dentro de casa [...] (C3, informação verbal).

[...] tem vez que passo a noite acordado cuidando dela [...] (C6) (informação verbal).

Nesses relatos, vê-se que a percepção da sobrecarga familiar aponta para o fato de os cuidadores perceberem os fatores psicológicos e emocionais decorrentes das alterações na rotina familiar, causadas pelos comportamentos da esposa. Entre essas alterações está a perda do sono, em decorrência da preocupação com o cuidado dispensado à parceira. Para Rosa (2011, p. 287), “[...] exatamente à noite é que a carga de preocupação do cuidador é maior, em virtude do risco de relaxar a intensidade da vigilância. Mas a necessidade de vigilância é permanente, o que exige um cuidador disponível temporalmente." Essa compreensão pode estar associada ao fato de o cuidador não saber lidar com a situação. Nesse caso, a preocupação passa a ser também com as suas atribuições como chefe de família, pois agora não dispõe de tempo suficiente para exercê-las: "Tem hora que a gente até precisa tomar remédio; eu mesmo estou precisando [...] precisava fazer um tratamento" (C1, informação verbal).

[...] você passa a se preocupar muito com a pessoa, me preocupo com ela e esqueço de mim; é aquela velha coisa: vou me preocupar com você e esquecer de mim. Mas pra mim está tudo bem; se eu comer ou não comer, se eu não fazer mais nada, então acho assim, acaba afetando. Você já não dorme direito, você não se alimenta direito, eu só trabalho na minha função, não faço mais esportes, não faço mais nada. Eu vi que começou a prejudicar meu corpo também, passar mal, certa falta de vontade de fazer as coisa, acaba até afetando, assim, no seu trabalho, você vai lá trabalha (C2, informação verbal).

Fica evidente que o homem, ao assumir o papel de cuidador de sua esposa, mediante o monitoramento das medicações, realização de cuidados e acompanhamento do tratamento, também precisa ser cuidado: “[...] é difícil; a pessoa que cuida fica quase tão doente quanto o doente [...]" (C3, informação verbal). Acrescente-se a fala de outro entrevistado, conforme o trecho a seguir:

Agora está mais fácil, porque hoje em dia tem telefone e tudo, mas no começo era mais difícil; tinha o dinheiro, mas não tinha como buscar as coisas, porque não tinha como levar ela. Tinha que ficar cuidando e tinha que esperar vir alguém pra poder ajudar a gente. Às vezes me sinto exausto, sabe? Tem hora que a gente fica mais doente que o doente ainda; tem que pedir muito a Deus pra dar uma força, engolir tudo e ficar quieto, deixar pra lá (C6, informação verbal).
Para esses cuidadores, o sofrimento psíquico da esposa impõe várias restrições em sua vida, gerando sobrecarrega física e emocional e, consequentemente, seu adoecimento mental.

\section{Sentimento de culpa pelo adoecimento da esposa}

Outra questão levantada foi o sentimento de culpa do cuidador pelo agravamento da doença da esposa. Para alguns dos entrevistados, a falta de compreensão dos primeiros sintomas e a negligência no início da doença foi considerada como fatores influenciadores na progressão do sofrimento da esposa. Sobre a questão da culpa, o cuidador C2 expõe:

[...] eu me sinto um pouco culpado, porque quando ela me falou pela primeira vez sobre algumas coisas que estava sentindo eu não dei importância. Até no momento achei que fosse uma coisa normal, passageira, e não era. Tanto que ela me falou algumas vezes que ia a uma psicóloga, marcou algumas consultas e foi, e eu não dei a devida atenção pra perguntar o que estava acontecendo. [...] e por eu não ter dado a devida atenção também ela acabou desistindo dessa parte. A culpa é minha, eu sei que tenho uma grande parcela, por isso que eu me propus ajudar ela agora (informação verbal).

Como a família é vista como espaço obrigatório dos afetos e sentimentos, sendo responsabilizada quase que integralmente pelo bem-estar e saúde dos seus integrantes (MACIEL et al., 2009), o adoecimento mental da esposa recai como responsabilidade do homem, abalando sua autoestima. Tal relato parece denunciar falhas no seu papel como marido e chefe da família, levando a um sentimento de que não conduziu com sucesso a sua missão de protetor.

Outro fator que chamou atenção foi relativo às condições socioeconômicas dos cuidadores. Apenas dois possuem renda superior a dois salários mínimos. Além disso, o nível de escolaridade também é baixo, a maioria é analfabeta e semianalfabeta, e a maior parte não está engajada em ocupações fora do lar. O que se percebe é que, para esses cuidadores, tal situação vulnerabiliza suas condições de autoridade moral na família, uma vez que sua identidade não está socialmente vinculada ao espaço doméstico, e se encontrar nessa situação configura perda do poder de "homem da casa", conforme depoimento a seguir: "Já pensou viver assim? Eu sou o homem daqui, eu sou o responsável por todos aqui. Que homem eu sou? Isso é horrível pra mim (C3, informação verbal).

Para Rosa (2011), as privações econômicas, que em geral antecedem as enfermidades nessas famílias, estão associadas cotidianamente ao analfabetismo, ao desemprego, à submoradia e ao estigma da pobreza. Nesse sentido, a provável dificuldade socioeconômica pode comprometer mais ainda a percepção desses cuidadores com relação à esposa doente, como um ser que sofre e que precisa ser confortado (OLIVEIRA; LUNARDI; SILVA, 2005).

Dito de outra forma, o cuidado com a esposa em sofrimento psíquico pode influenciar de forma negativa as condições emocionais do cuidador quando as exigências materiais são escassas ou inexistentes, uma realidade das famílias com poucos recursos financeiros. No aspec- 
to laboral, a falta de dinheiro e de sucesso profissional do homem cuja ocupação é o cuidado com a esposa em sofrimento mental ocasiona a possibilidade de seu sofrimento, marcada pela ausência de valor da sua eficiência (ZANELLO, 2014).

Em uma perspectiva geral, os achados deste estudo mostram que a contemporaneidade tem proporcionado mudanças socioculturais nas rotinas de homens e mulheres que afetam o modo de vida e o desempenho de papéis sociais dos indivíduos, como apontam Arruda e Lima (2013), entre eles a atividade de cuidador. E nessa conjuntura a função de cuidador parece iniciar um período de transição nos valores familiares, já que a mulher era a única responsável pelo cuidado de um membro enfermo. Nessa nova concepção, ainda que lentamente, o universo masculino tem se aproximado do universo feminino, rompendo com a construção social da divisão sexual do trabalho, a qual era firmada de acordo com a posição que cada indivíduo ocupava no grupo conforme o sexo, estabelecendo um novo lugar para o homem, relacionado ao papel de cuidador.

Além disso, os desafios enfrentados pelos cônjuges não diferem daqueles apontados pelas mulheres cuidadoras, como mostram outras pesquisas (DOURADO et al., 2018; SANT'ANA et al., 2011). Tal constatação pode ser evidenciada a partir das ideias trazidas pelos cuidadores, que convergiam perante as dificuldades vividas, na falta de conhecimento diante do sofrimento psíquico da esposa. Embora cada um desses homens tenha uma história de vida construída pelas suas particularidades, todos demonstraram as dificuldades enfrentadas no cotidiano, evidenciadas pela constituição adicional da sobrecarga financeira, física e/ou emocional.

A sobrecarga física seria oriunda do aumento dos novos encargos e afazeres domésticos e cuidados com a esposa. Já a sobrecarga psicológica seria vivida em razão do aumento das emoções, como julgamentos, censuras e incompreensões, além das alterações nas atividades de lazer e nas relações sociais da família. Todos esses fatores mostram o cuidado como um lugar de potencial adoecimento para esses homens, lugar esse que, historicamente, foi naturalizado às mulheres.

Por outro lado, ao contrário da mulher, quando o homem é o cuidador principal da esposa, existe uma tendência de vir a abandoná-la (ROSA, 2011). Neste estudo foi possível constatar que vários cuidadores tiveram o desejo de internar a esposa. Tal desejo pode ser entendido como possível alívio da sobrecarga, gerada pelo novo papel de cuidador e pelo convívio conturbado na relação conjugal com a esposa em sofrimento psíquico. Além disso, a minoria dos entrevistados demonstrou acreditar na melhora da esposa; os demais tinham desesperança quanto à perspectiva de tratamento e à obtenção de bons resultados com o tratamento. $\mathrm{O}$ cuidador vê o cuidado com a esposa como uma obrigação inerente ao contrato matrimonial; alguns cuidadores justificaram o seu papel porque "já estão de idade" ou "não tem quem cuida dela" (informações verbais).
Seja de forma explícita, seja nas entrelinhas, foi possível reconhecer, nos discursos dos participantes deste estudo, a necessidade de apoio e de investimentos por parte dos serviços públicos no atendimento ao cuidador familiar. O cuidador tem em si o seu mais importante e único instrumento de trabalho. O cuidado a essa população, por meio da atenção à sua saúde, promove o bom andamento e a qualidade no desempenho do seu papel como cuidador.

A discussão dessas questões se torna bastante relevante se for levado em consideração que a política de saúde mental traz em seu bojo a criação de programas que têm por finalidade a exclusividade do atendimento à família de pessoas que se encontram em sofrimento psíquico. Assim, o que se busca apontar é a necessidade de ações que promovam a discussão acerca do assunto, articuladas entre profissionais, usuários e comunidade, a fim de se vislumbrar a inserção de tais questionamentos na pauta permanente das discussões no campo da atenção à saúde do cuidador familiar.

Entende-se que os profissionais de saúde, além de fazerem parte da rede social dos cuidadores, ao atuarem de forma coordenada com os demais componentes dessa rede, têm a possibilidade de colaborar para a diminuição da sobrecarga do cuidador familiar e, consequentemente, do seu adoecimento. Nessa direção, entende-se que a identificação do cuidador e da posição que este ocupa no grupo familiar, considerando sexo, idade e grau de parentesco, é fundamental para a criação de estratégias de cuidado, não só do familiar em tratamento, mas sobretudo do próprio cuidador.

\section{Considerações finais}

Durante todo o percurso deste estudo, buscou-se compreender e discutir o papel do cuidador familiar do sexo masculino a partir das suas experiências vividas perante as demandas oriundas do cuidado com a esposa que se encontrava em sofrimento psíquico grave.

$\mathrm{O}$ acesso à história de vida de cada participante se deu em encontros, permeados de emoção, de sentimento de empatia e de tristeza. Muitas vezes foi preciso "escutar o silêncio" do entrevistado. Silêncio carregado de emoção e de tristeza no olhar que revelou a desesperança e o desânimo do desejo de lutar. Ou seja, os contornos não definidos, a incerteza, a instabilidade do estado emocional da esposa, a rotina cotidiana de modo irregular conferem ao cuidador descontinuidade na idealização de recuperação da saúde da parceira, uma vez que ele se vê impossibilitado de fazer planos futuros.

Muitas entrevistas foram interrompidas pelo choro e, até mesmo, pela raiva. Raiva não da esposa doente, mas do momento em que se encontrava esse cuidador. Pode-se pensar que tal situação também deve ser entendida como uma consequência relativa ao desamparo provocado pela política na área de saúde mental, pela estigmatização da doença e pelo preconceito ainda existente contra aquele que se encontra em plena vulnerabilidade da saúde mental. 
O sentimento de raiva como expressão do estado emocional dos cuidadores revelou-se, em outros momentos, por sentimentos como a irritação, ou até mesmo a fúria, diante da sensação de impotência e da interpretação da vida como vazia de sentido. Os relatos dos cuidadores mostraram que a compreensão acerca do cuidado com a esposa em sofrimento mental precisou ser desenvolvida ao longo do tempo. Eles reconheceram que, no início, o sofrimento das companheiras gerou insegurança, incerteza, medo, dúvida e preocupação.

Assim, as informações coletadas revelaram as dificuldades encontradas na convivência cotidiana do âmbito familiar; apontaram várias dificuldades referentes ao cuidado com a esposa em sofrimento psíquico, principalmente a relacionada ao fato de ter que, praticamente, abdicar de sua vida para exercer o papel de cuidador.

No que se refere à percepção do papel de cuidador na relação conjugal, os sentidos produzidos pelos entrevistados foram diversos e demonstraram concepções variadas de cuidar que resultam da reeleição de estratégias de enfrentamento da doença e de busca de recursos bastante diversificados. Alguns compreendem que seu papel como cuidador da esposa é uma missão a ser cumprida. Para estes, embora essa função anule parcialmente seus sonhos, sua vida social e profissional, gerando uma sobrecarga e podendo levá-los, até mesmo, a um estado de adoecimento, o cuidar representa uma obrigação que foi firmada no ato matrimonial, levando-os a desenvolver uma relação baseada na paciência, no amor, no respeito, na confiança, no conhecimento e, sobretudo, na esperança.

Para outros, o ato de cuidar da esposa é representado por uma experiência negativa, que mobiliza sofrimento, frustração, sobrecarga, desesperança, adoecimento e constitui, para a maioria dos cuidadores entrevistados, uma experiência pouco enriquecedora, levando-os a apresentar sintomas físicos e emocionais de desgaste ao assumirem o cuidar do outro. Para esse último grupo, fica evidente o desejo de internação da esposa como forma de alívio.

Ficou evidenciado, ainda, que o estigma sobre a doença mental é fator que interfere no desempenho dos cuidadores, sendo estes também alvo do preconceito social, ficando relegados ao isolamento da família. Fatores geradores de sobrecargas psicológicas, como abdicação da vida social e do trabalho, entre outros, incidem sobre os cuidadores, criando condições propícias para o seu adoecimento.

Dessa maneira, este trabalho pode favorecer outras reflexões acerca dos sentidos que foram construídos, em direção às propostas de atenção aos cuidadores, e contribuir para fornecer ao leitor percepções acerca dos sentidos que são produzidos pelos cônjuges cuidadores, no campo da saúde mental, podendo servir de ferramenta para as construções teóricas e práticas que abordam esse tema.

Ao finalizar este trabalho, sugere-se que haja desenvolvimento de estratégias de atendimento aos cuidadores, com a finalidade de instrumentalizá-los para lidar de forma mais adequada com seus familiares. Sugere-se, ainda, a criação de espaços que promovam a troca de experiências e habilidades com relação ao papel de cuidador que cada um desenvolveu ao longo do tempo.

E, por último, e não menos importante, entende-se que este estudo pode possibilitar reflexões sobre o papel do homem e da mulher como forma homogênea no cuidado, desejando-se que as orientações dos profissionais da saúde mental sirvam de referência diante das vivências cotidianas com a parceira em sofrimento mental, pois dessa forma será possível reduzir suas angústias com relação ao cuidar e ao sofrimento do outro.

\section{Informações sobre o autor: \\ Eraldo Carlos Batista \\ (iD) http://orcid.org/0000-0002-7118-5888 \\ (9) http://lattes.cnpq.br/9520124935598363}

Possui Graduação em Psicologia (Faculdade de Rolim de Moura - FAROL, 2013), Especialização em Metodologia e Didática do Ensino Superior (Faculdade de Rolim de Moura - FAROL, 2013) e Saúde Mental (Universidade Católica Dom Bosco - UCDB, Campo Grande - MS), Mestrado em Psicologia (Universidade Federal de Rondônia - UNIR), Doutorado em Psicologia Social (Pontifícia Universidade Católica - PUCRS/Faculdade Católica de Rondônia FCR). Tem interesse em Psicologia Social e Saúde Mental.

\section{Como citar este artigo:}

\section{ABNT}

BATISTA, Eraldo Carlos. Experiências vividas pelo cônjuge cuidador da esposa em tratamento psiquiátrico. Fractal: Revista de Psicologia, Niterói, v. 32, n. 1, p. 31-39, jan./abr. 2020. https://doi. org/10.22409/1984-0292/v32i1/5646

\section{APA}

Batista, E. C. (2020, Janeiro/Abril). Experiências vividas pelo cônjuge cuidador da esposa em tratamento psiquiátrico. Fractal: Revista de Psicologia, 32(1), 31-39. doi: https://doi. org/10.22409/1984-0292/v32i1/5646

\section{Referências}

ARRUDA, Sérgio Luiz Saboya; LIMA, Manuela Caroline Ferreira. O novo lugar do pai como cuidador da criança. Estudos Interdisciplinares em Psicologia, v. 4, n. 2, p. 201-216, 2013. Disponível em: http://pepsic.bvsalud.org/pdf/eip/v4n2/ a06.pdf. Acesso em: 19 set. 2019.

BATISTA, Cynthia Mara Felicio et al. Sobrecarga de familiares de pacientes psiquiátricos: influência do gênero do cuidador. Cadernos Saúde Coletiva, v. 21, n. 4, p. 359-369, 2013. http:// dx.doi.org/10.1590/S1414-462X2013000400002.

BORIS, Georges Daniel Janja Bloc. Falas de homens: a construção da subjetividade masculina. 2. ed. São Paulo: Annablume, 2011

CAMPOS, Pedro Humberto Faria; SOARES, Carlene Borges. Representação da sobrecarga familiar e adesão aos serviços alternativos em saúde mental. Psicologia em Revista, Belo Horizonte, v. 11, n. 18, p. 219-237, dez. 2005. Disponível em: $\quad$ http://pepsic.bvsalud.org/scielo.php?script=sci arttext\&pid=S1677-11682005000200006\&lng=pt\&nrm=iso. Acesso em: 21 set. 2015. 
CARDOSO, Lucilene; GALERA, Sueli Aparecida Frari; VIEIRA, Mariana Verderoce. O cuidador e a sobrecarga do cuidado à saúde de pacientes egressos de internação psiquiátrica. Acta Paul. Enferm., v. 25, n. 4, p. 517-523, 2012. Disponível em: http://www.scielo.br/pdf/ape/v25n4/en_06.pdf. Acesso em: 12 out. 2013.

CATTANI, Roceli Brum; GIRARDON-PERLINI, Nara Marilene Oliveira. Cuidar do idoso doente no domicílio na voz de cuidadores familiares. Revista Eletrônica de Enfermagem, v. 6, n. 2, p. 254-271, 2004. Disponível em: http://www.fen. ufg.br/revista/revista6_2/pdf/Orig11_idoso.pdf. Acesso em: 22 jan. 2016.

DIAS, Elenise Aparecida. Sobrecarga vivenciada por familiares cuidadores de pacientes esquizofrênicos e sua relação com a depressão. 2011. 168 f. Dissertação (Mestrado em Saúde Mental) - Faculdade de Ciências Médicas da Universidade Nova de Lisboa, Lisboa, 2011.

DOURADO, Denise Martins et al.; Ansiedade e depressão em cuidador familiar de pessoa com transtorno mental. ECOSEstudos Contemporâneos da Subjetividade, v. 8, n. 1, p. 153167, 2018. Disponível em: http://www.periodicoshumanas.uff. br/ecos/article/view /2377. Acesso em: 17 set. 2019.

FLICK, Uwe. Introdução à pesquisa qualitativa. 3. ed. Porto Alegre: Artmed, 2009.

GOMES, Maria Lovâni Pereira; SILVA, José Carlos Barboza da; BATISTA, Eraldo Carlos. Escutando quem cuida: quando o cuidado afeta a saúde do cuidador em saúde mental. Revista Psicologia e Saúde, v. 10, n. 1, p. 3-7, 2018. Disponível em: http://pepsic.bvsalud.org/pdf/rpsaude/v10n1/v10n1a01.pdf. Acesso em: 17 set. 2019.

LACCHINI, Annie Jeanninne Bisso. A família que cuida do indivíduo em sofrimento psíquico: um estudo fenomenológico. 2011. 103 f. Dissertação (Mestrado em Enfermagem) Universidade de Santa Maria, Santa Maria, 2011. Disponível em: https://repositorio.ufsm.br/handle/1/7340. Acesso em: 21 set. 2015 .

LISBOA, Aline Vilhena; FÉRES-CARNEIRO Terezinha ...Até que a doença nos separe? A conjugalidade e o adoecer somático. Psico, v. 39, n. 1, p. 83-90, jan./mar. 2008. Disponível em: https://dialnet.unirioja.es/servlet/articulo? codigo $=5161445$. Acesso em: 29 abr. 2016.

MACIEL, Silvana Carneiro et al. Reforma psiquiátrica e inclusão social: um estudo com familiares de doentes mentais. Psicologia: ciência e profissão, Brasília, v. 29, n. 3, p. 436-447, 2009. http://dx.doi.org/10.1590/S1414-98932009000300002

MELMAN, Jonas. Família e doença mental: repensando a relação entre profissionais saúde e de seus familiares. São Paulo: Escrituras, 2001.

MINAYO, Maria Cecília de Souza. O desafio do conhecimento: pesquisa qualitativa em saúde. 12. ed. São Paulo: Hucitec, 2010.

MOREIRA, Daniel Augusto. O Método fenomenológico na pesquisa. São Paulo: Pioneira Thomson Learning, 2004.

NORGREN, Maria de Betânia Paes et al. Satisfação conjugal em casamentos de longa duração: uma construção possível. Estudos de Psicologia, Natal, v. 9, n. 3, p. 575-584, 2004. http:// dx.doi.org/10.1590/S1413-294X2004000300020
OLIVEIRA, Adriane Maria Netto de; LUNARDI, Valéria Lerch; SILVA, Mara Regina Santos da. Repensando o modo de cuidar do ser portador de doença mental e sua família a partir de Heidegger. Cogitare Enferm, v. 10, n. 1, p. 9-15, 2005. Disponível em: http://ojs.c3sl.ufpr.br/ojs/index.php/cogitare/ article/viewFile/4661/3617. Acesso em: 27 abr. 2015.

ROSA, Lúcia Cristina dos Santos. Transtorno mental e o cuidado na família. 3. ed. São Paulo: Cortez, 2011.

SANDERS, Patricia B. Phenomenology: a new way of viewing organizational research. Academy of Management Review, v. 7, n. 3, p. 353-360, 1982. https://doi.org/10.5465/ amr.1982.4285315

SANT'ANA, Marília Mazzuco et al . O significado de ser familiar cuidador do portador de transtorno mental. Texto \& contexto - Enfermagem, Florianópolis, v. 20, n. 1, p. 50-58, 2011. http://dx.doi.org/10.1590/S0104-07072011000100006

SEVERO, Ana Kalliny de Souza et al. A experiência de familiares no cuidado em saúde mental. Arquivos Brasileiros de Psicologia, v. 59, n. 2, 2007. Disponível em: http://pepsic. bvsalud.org/pdf/arbp/v59n2/v59n2a05.pdf. Acesso em: 6 out. 2015.

SILVA, Victor Hugo Farias da; DIMENSTEIN, Magda; LEITE, Jáder Ferreira. $\mathrm{O}$ cuidado em saúde mental em zonas rurais. Mental, v. 10, n. 19, p. 267-285, 2013. Disponível em: http:// www.redalyc.org/articulo.oa?id=42028699008. Acesso em: 21 jan. 2016.

ZANELLO, Valeska. A saúde mental sob o viés do gênero: uma releitura gendrada da epidemiologia, da semiologia e da interpretação diagnóstica. In: ZANELLO, Valeska; ANDRADE, Ana Paula Muller de (Org.). Saúde mental e gênero: diálogo, práticas e interdisciplinaridade. Curitiba: Appris, 2014. p. 4158. 